\title{
Época apropriada para a poda apical do algodoeiro para o controle de pragas
}

\author{
Robério Carlos dos Santos Neves(1), Jorge Braz Torres ${ }^{(1)}$ e Melchior Naelson Batista da Silva(2)
}

(1)Universidade Federal Rural de Pernambuco, Departamento de Agronomia-Entomologia, Rua Dom Manoel de Medeiros, s/no, Dois Irmãos, CEP 52171-900 Recife, PE. E-mail: roberiocneves@oi.com.br, jtorres@depa.ufrpe.br (2)Embrapa Algodão, Rua Osvaldo Cruz, no 1.143, Centenário, CEP 58107-720 Campina Grande, PB. E-mail: melchior@cnpa.embrapa.br

Resumo - O objetivo deste trabalho foi determinar a época apropriada para a realização da poda apical em algodoeiro. O trabalho foi realizado durante as safras de 2008 e 2009 (maio a novembro) em delineamento de blocos ao acaso, em dois ambientes, com as variedades: BRS 201, de fibra branca, e BRS Rubi, BRS Safira e BRS Verde, de fibra colorida, em Paudalho, PE; e BRS 201 e BRS Rubi, em Surubim, PE. A poda apical consistiu na retirada dos ápices das plantas com estruturas vegetativas e reprodutivas, em duas idades fenológicas: com $50 \%$ das maçãs maduras (poda I) e no surgimento dos primeiros capulhos (poda II). A poda I resultou em maior retirada de botões florais do que a poda II. Em ambas as podas, houve a retirada de cinco nós dos ponteiros. A produção e a qualidade de fibra não diferiram entre plantas podadas ou não. Um número significativo de estruturas atacadas foi eliminado pela poda. A poda apical é recomendada para reduzir o número de estruturas não produtivas, ao final da safra, que são utilizadas como hospedeiras de pragas.

Termos para indexação: Gossypium hirsutum, algodão colorido, controle cultural, manejo integrado de pragas.

\section{Appropriate time for pruning cotton plant aiming at pest control}

\begin{abstract}
The objective of this work was to determine the appropriate time to prune the terminal portions of the cotton plants. The work was carried out during 2008 and 2009 (May-November) growing seasons in a randomized block design in two environment, with the varieties: BRS 201, of white fibers, and the colored fiber varieties BRS Rubi, BRS Safira, and BRS Verde, in Paudalho, PE, Brazil; and BRS 201 and BRS Rubi, in Surubim, PE, Brazil. Pruning consisted in excising the apices with the vegetative and reproductive structures, at two plant ages: with 50\% mature bolls (prune I), and at the opening of the first boll (prune II). Prune I resulted in greater excision of flower buds than prune II. In both prunings, five nodes from the plant apex were excised. Yield and fiber quality did not differ between pruned and nonpruned plants. A significant number of infested structures was removed by pruning. Pruning can be recommended to reduce nonproductive structures that can, at the end of the season, be used as hosts for important pests.
\end{abstract}

Index terms: Gossypium hirsutum, naturally colored cotton, cultural control, integrated pest management.

\section{Introdução}

O cultivo do algodoeiro herbáceo (Gossypium hirsutum L.) no Semiárido apresenta baixo uso de insumos agrícolas e é realizado, em sua maioria, por pequenos produtores, nos moldes da agricultura familiar (Santos et al., 2008b). Por isso, requer tecnologias de fácil adoção para o controle de pragas, que é fator limitante ao cultivo do algodão na Região, com destaque para o bicudo-do-algodoeiro, Anthonomus grandis Boh. (Coleoptera: Curculionidae) (Ramalho, 1994; Santos et al., 2008b).

A cultura do algodão no Nordeste tem custos de produção considerados muito baixos, quando cultivado no sistema de sequeiro, pois poucos insumos são usados até mesmo para o controle de pragas. Nesse contexto, práticas culturais de fácil adoção pelos agricultores devem ser aprimoradas e implantadas, para um melhor controle das pragas da cultura e proteção dos inimigos naturais (Ramalho et al., 2000; Torres \& Ruberson, 2004; Wanderley et al., 2007; Neves et al., 2009).

O plantio do algodoeiro de fibra colorida, com grande apelo do ponto de vista social e ambiental, tem contribuído para aumentar a demanda pelas fibras coloridas e elevado seu valor de comercialização em relação à fibra branca (Carvalho, 2008). Portanto, o cultivo das variedades de fibras coloridas poderá trazer vantagens aos produtores da região (Beltrão \& Carvalho, 2004). 
Insetos e ácaros utilizam o algodoeiro como hospedeiro, com destaque para algumas pragas importantes que ocorrem com maior frequência nos diversos sistemas de cultivo no Semiárido. $\mathrm{O}$ ataque de pragas, em especial após a introdução do bicudo-do-algodoeiro, é uma das principais causas da redução da área plantada com algodão no Semiárido (Ramalho, 1994). Entre as práticas culturais utilizadas para o cultivo do algodoeiro, a manipulação da densidade de plantio, a época de plantio, a adoção de variedades precoces, a retirada de plantas invasoras e a rotação de culturas favorecem o manejo correto de pragas (Gallo et al., 2002; Silvie et al., 2006; Almeida et al., 2008). Outras práticas incluem a catação e a destruição das estruturas reprodutivas caídas ao solo e dos restos culturais.

O algodoeiro herbáceo possui crescimento indeterminado, o que resulta na presença de estruturas reprodutivas de diferentes idades em uma mesma planta. Os ramos vegetativos e reprodutivos continuam a se desenvolver e a produzir botões florais na parte apical da planta, concomitantemente com o surgimento dos primeiros capulhos na parte basal (Beltrão et al., 2008). De acordo com Arruda et al. (2002), apenas 44\% dos botões florais produzidos formam capulhos. Quando não há abscisão natural, o excesso dessas estruturas permanece nas plantas e serve como alimento, sítio de oviposição e habitat de pragas.

A poda apical, realizada após a formação das maçãs que irão formar capulhos, reduz o ramo monopodial e os ramos simpodiais e pode diminuir a população de insetos-praga na lavoura e melhorar a produção. A retirada de estruturas jovens da planta pode reduzir a atratividade e suprimir os sítios de oviposição e de desenvolvimento de insetos (Deguine et al., 2000; Sundaramurthy, 2002). Pode, também, afetar o crescimento e o desenvolvimento da planta (Obasi \& Msaakpa, 2005) e modificar a distribuição dos assimilados, em benefício das maçãs mais antigas (Kim \& Oosterhuis, 1998), além de sincronizar a abertura de capulhos (Bednarz \& Roberts, 2001), o que tem reflexos sobre a quantidade e a qualidade das fibras produzidas (Deng et al., 1991; Brown et al., 2001).

A hipótese testada neste trabalho é a de que a retirada de estruturas do ponteiro, pela poda apical em época adequada, não afeta a produção e a qualidade da fibra do algodão. Em consequência, espera-se que o manejo de pragas seja facilitado com a retirada do ponteiro das plantas e dos botões atacados, em razão do potencial efeito sobre infestações do bicudo e de pragas dos ponteiros, como os pulgões, os ácaros e outros comumente associados a essas partes da planta de algodão.

O objetivo deste trabalho foi determinar a época apropriada para a poda apical em plantas de algodão.

\section{Material e Métodos}

O experimento foi realizado durante as safras de 2008 e 2009 (maio a novembro), em duas áreas experimentais. Em 2008, o experimento foi realizado em Aldeia, Município de Paudalho, PE e, em 2009, em Furnas, Município de Surubim, PE. A área experimental de Aldeia está situada na Zona da Mata a $07^{\circ} 56^{\prime} 26^{\prime \prime} \mathrm{S}$ e $35^{\circ} 10^{\prime} 39^{\prime \prime} \mathrm{W}$, e a área de estudo de Furnas está situada no Semiárido a $07^{\circ} 53^{\prime} 49^{\prime \prime} \mathrm{S}$ e $35^{\circ} 49^{\prime} 19^{\prime \prime} \mathrm{W}$. A precipitação foi monitorada com pluviômetro nas áreas plantadas e a temperatura e a umidade relativa do ar foram medidas com Datalogger HOBO (Onset Computer Corp., Bourne, MA, EUA), a cada 30 min.

Durante a safra de 2008, em Paudalho, a temperatura média \pm erro-padrão foi de $27,0 \pm 1,2{ }^{\circ} \mathrm{C}$, a umidade relativa de $84,0 \pm 8,0 \%$, com precipitação acumulada de $1.117 \mathrm{~mm}$, entre 24 de maio e 22 de outubro (acumulada em 157 dias). Em Surubim, durante a safra de 2009 , a temperatura média foi de $24,3 \pm 0,9^{\circ} \mathrm{C}$, a umidade relativa média $65,0 \pm 13,0 \%$, e a precipitação acumulada entre 1을 de maio e 22 de setembro foi de $403 \mathrm{~mm}$ (acumulada em 144 dias).

O preparo da área de plantio para a safra de 2008 foi feito com aração e gradagem. O plantio da área foi feito manualmente, em 24 de maio de 2008, com espaçamento de $1 \mathrm{~m}$ entre linhas e com duas ou três covas por metro, compatível com o sistema adotado na região, para facilitar o controle de plantas invasoras com cultivador movido à tração animal. A semeadura foi feita com três a quatro sementes por cova, tendo-se sobreposto $300 \mathrm{~g}$ de esterco bovino curtido em cada cova. O desbaste foi realizado nos $12^{\circ}$ e $20^{\circ}$ dias após o plantio (DAP), durante a capina manual, tendo-se deixado uma planta por cova. O controle de plantas daninhas e a amontoa foram feitos manualmente, com auxílio de enxada, com três capinas durante o ciclo da cultura. Nenhum tipo de controle químico ou biológico foi usado para o controle de pragas.

$\mathrm{O}$ experimento foi instalado em delineamento de blocos ao acaso, com três repetições. Foram avaliadas 
quatro variedades de algodão: BRS 201, de fibra branca; BRS Rubi, de fibra marrom escura; BRS Safira, de fibra marrom clara; e BRS Verde, de fibra verde. As parcelas foram compostas por seis fileiras com $10 \mathrm{~m}$ de comprimento $\left(60 \mathrm{~m}^{2}\right)$, com duas fileiras de milho híbrido AG 122 na bordadura.

Foram comparadas plantas que receberam ou não a poda apical. Nos tratamentos que receberam a poda apical, no experimento de Paudalho, PE, em 2008, a poda foi avaliada em duas épocas. Para tanto, três fileiras foram podadas quando apresentaram $50 \%$ de maçãs maduras (poda I), e as três fileiras remanescentes foram podadas na abertura dos primeiros capulhos (poda II). A poda apical consistiu na retirada do ponteiro do ramo monopodial (vegetativo) e dos ramos simpodiais (frutíferos) com folhas, botões florais, flores e maçãs com até $1 \mathrm{~cm}$ de diâmetro.

Na poda apical da safra de 2008, as avaliações foram feitas a partir do $60^{\circ}$ dia após plantio, a intervalos de aproximadamente 14 dias. Nas primeiras avaliações, foram inspecionadas dez plantas em cada parcela, que serviram como parâmetro de desenvolvimento das plantas, tendo-se avaliado o número de nós e a produção de estruturas reprodutivas.

No momento da poda, amostras dos ponteiros e respectivas estruturas, obtidas das plantas localizadas na fileira central de cada repetição, foram acondicionadas em sacos de plástico identificados quanto à variedade, bloco e época de poda, e transportados para o Laboratório de Controle Biológico e Ecologia de Insetos, da Universidade Federal Rural de Pernambuco. No laboratório, foi realizada a inspeção total dos ponteiros para determinar o número de estruturas reprodutivas e vegetativas e a existência de insetos-praga retirados com as duas podas. No campo, sete dias após a poda, o número de estruturas reprodutivas (maçãs e capulhos) e de nós por planta foi determinado mediante a inspeção visual de quatro a seis plantas por parcela.

Aos 150 dias após o plantio, procedeu-se à colheita de capulhos oriundos de plantas presentes em $1 \mathrm{~m}$ de fileira de cada parcela, e as estruturas obtidas foram usadas para determinar o número de capulhos por planta e os parâmetros de qualidade de fibra e fio. Os capulhos colhidos foram acondicionados em sacos de papel, identificados e enviados ao Laboratório de Fibras e Fio da Embrapa Algodão, Campina Grande, $\mathrm{PB}$, onde foram realizadas análises para determinar peso de rama, peso de pluma, peso de um capulho, percentagem de fibras e parâmetros qualitativos da fibra, tais como comprimento, uniformidade, resistência e índice Micronaire.

$\mathrm{Na}$ safra de 2009, o plantio da área foi realizado de forma manual, no dia $1^{\circ}$ de maio de 2009, com espaçamento de $1 \mathrm{~m}$ entre linhas e de duas a três covas por metro linear. Foram depositadas de quatro a cinco sementes por cova com desbaste em 15 de maio de 2009, tendo-se deixado apenas duas plantas por cova. Aos trinta DAP, foi feito o controle de plantas daninhas, com cultivador de tração animal, e foram feitos retoques com enxada na linha de plantio. A adubação de plantio foi realizada na cova com aproximadamente $6 \mathrm{~g}$ de NPK 04-14-08, seguida pelo recobrimento do fertilizante, deposição das sementes e cobertura com solo. A adubação de cobertura foi feita com aproximadamente $6 \mathrm{~g}$ de sulfato de amônia por cova. Aos 45 e 95 DAP, foi feito o controle de plantas daninhas com capina manual.

Os tratamentos resultantes da combinação de duas variedades e poda apical foram dispostos em delineamento de blocos ao acaso, com três repetições. Cada bloco teve duas parcelas cultivadas com as variedades BRS 201 e BRS Rubi que, posteriormente, foram submetidas aos tratamentos com ou sem poda apical. As parcelas foram compostas por 12 fileiras com $44 \mathrm{~m}$ de comprimento $\left(528 \mathrm{~m}^{2}\right)$. Na bordadura da lavoura, entre os blocos e parcelas, foi realizado o plantio de três fileiras de milho híbrido AG 122 .

$\mathrm{Na}$ safra de 2009, as avaliações foram feitas a cada 12 dias, a partir dos 30 DAP, em dez plantas selecionadas ao acaso por parcela. O desenvolvimento das plantas foi monitorado pelo número de nós e estruturas reprodutivas presentes. As plantas foram submetidas à poda apical quando apresentavam 50\% de maçãs maduras, correspondente aos 115 DAP.

Os ponteiros retirados pela poda foram recolhidos e pesados. Amostras desses ponteiros, atacadas ou não pelo bicudo (com sinais de oviposição e alimentação) e demais insetos-praga, retirados com a poda apical, foram acondicionadas em sacos de plástico. Foram, ainda, identificadas quanto ao bloco e variedade, e levadas ao laboratório para determinação do número de folhas, botões e maçãs. Capulhos das plantas localizadas em $1,5 \mathrm{~m}$ da fileira central de cada parcela também foram colhidos após $150 \mathrm{DAP}$, para se determinar o número de capulhos colhidos por planta. 
Os dados obtidos nas localidades foram submetidos aos testes de normalidade (teste de Kolmogorov) e de homogeneidade da variância (teste de Bartlett) e, se necessário, transformados para atender aos requisitos da análise de variância (ANOVA). As médias foram comparadas pelo teste de Tukey, em caso de significância do efeito de tratamento sobre as características avaliadas. $\mathrm{O}$ teste $\mathrm{t}$ foi utilizado nos casos de comparação de apenas duas médias. Todas as análises foram conduzidas com o programa SAS (SAS Institute, 2001).

\section{Resultados e Discussão}

A variação nas condições climáticas entre as localidades justifica as diferenças na época das podas, entre Paudalho, em 2008, e Surubim, em 2009. O regime de chuvas e as médias de temperatura e de umidade relativa estavam dentro do padrão aceitável para o bom desenvolvimento do algodoeiro. Isso aumenta a importância da definição da poda a partir de características morfológicas das plantas (idade fenológica) e não pelo tempo decorrido após o plantio, que pode variar em razão das condições edafoclimáticas.

Na safra de 2008, o desenvolvimento das plantas, expresso em termos do número de nós sete dias após as podas, foi semelhante entre as variedades podadas com $50 \%$ de maçãs maduras $(14,7 \pm 1,00)$ e na abertura dos primeiros capulhos 15 dias mais tarde $(15,1 \pm 1,57)$ (Figura $1 \mathrm{~A}$ ). $\mathrm{O}$ número de botões florais removidos foi maior com a retirada de ponteiros na poda I, enquanto a poda II removeu maior quantidade de folhas (Figura $1 \mathrm{~B}$ ).
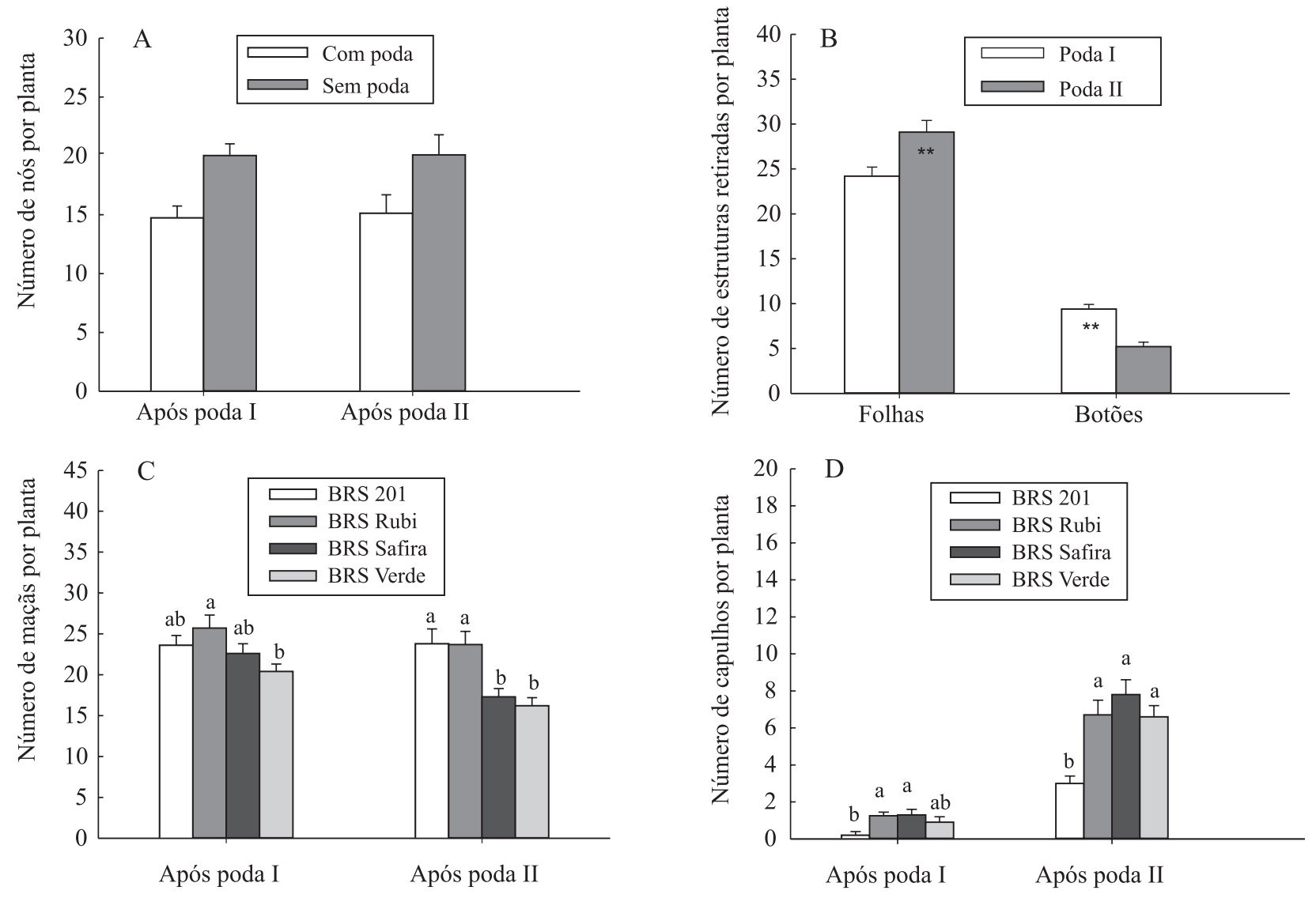

Figura 1. Média \pm erro-padrão do número de partes vegetativas e reprodutivas existentes e retiradas das plantas de algodão, com a realização das podas com 50\% de maçãs maduras (Poda I) e com a abertura dos primeiros capulhos (Poda II), para as respectivas variedades de algodão de fibra branca (BRS 201) e colorida, na safra 2008, em Paudalho, PE. **Indica diferença pelo teste de Fisher, a 1\% de probabilidade, entre tratamentos com e sem poda e entre podas I e II. Barras sob letras iguais, não diferem entre si, pelo teste Tukey, a 5\% de probabilidade. 
A poda e as épocas de poda não afetaram o número de maçãs desenvolvidas, mas o número de maçãs variou entre as variedades estudadas. Na poda com $50 \%$ de maçãs maduras, as variedades BRS Rubi e BRS Verde apresentaram, respectivamente, o maior e o menor número de maçãs. As variedades BRS Safira e BRS 201 apresentaram valores intermediários (Figura $1 \mathrm{C}$ ). Na poda com os primeiros capulhos, as variedades BRS 201 e BRS Rubi tiveram maior número de maçãs, em relação às variedades BRS Verde e BRS Safira.

O número de capulhos por planta foi semelhante entre os tratamentos com e sem poda, nas duas épocas, porém variou entre as variedades testadas. Após a poda I, a BRS Rubi e a BRS Safira apresentaram maior número de capulhos por planta do que a BRS 201, com a BRS Verde como intermediária (Figura 1 D). Tendência semelhante foi observada após a poda II, com a BRS 201 que continuou a apresentar o menor número de capulhos, e diferiu estatisticamente das outras três variedades.

Ao final do experimento, aos 150 DAP, o número de capulhos colhidos por planta foi semelhante entre as duas épocas de poda e entre plantas com e sem poda. Da mesma forma, o número de capulhos colhidos foi semelhante entre as variedades, com ou sem poda.

Os resultados de produção das quatro variedades, expressos como peso de rama, peso de pluma e peso de um capulho variaram de 81,6 a 128,8 g por planta, 27,1 a 45,4 g por planta e 3,5 a 5,6 g por capulho, respectivamente, e não diferiram entre plantas com e sem poda. A qualidade da fibra medida pela percentagem de fibra (variação de 29,1 a 44,2\%), comprimento de fibra (21,3 a 29,5 mm), uniformidade (80,8 a 85,0\%), resistência (20,0 a 28,8 gf/tex) e índice de Micronaire $(2,6$ a 4,6) não diferiram entre plantas com e sem poda, nas variedades estudadas.
A adoção da poda I retirou, em média, 24 folhas do ponteiro, das quais $48,2 \%$ infestadas por pulgão (Aphis gossypii), e 1,35\% pelo ácaro-vermelho (Tetranychus gloveri). Na poda II, foram retiradas, em média, 28 folhas, das quais $71,2 \%$ infestadas com o pulgão e 13,7\% infestadas com ácaro-vermelho. Assim, uma maior percentagem de folhas com pulgão foi retirada da planta no momento da realização da poda II, com exceção da variedade BRS 201 na qual não houve diferença estatística ( $p>0,05)$ na quantidade de folhas infestadas removidas pelas podas (Tabela 1).

Em 2009, a redução média foi de aproximadamente cinco nós na BRS 201 e seis na BRS Rubi (Figura 2 A). A quantidade de material retirado pela poda apical foi semelhante entre as variedades e variou de 10 a 12 folhas e de 3 a 4 botões florais por planta. A poda não alterou o número de maçãs remanescentes entre plantas com e sem poda nas variedades BRS Rubi $(10,6)$ e BRS $201(8,6)$ (Figura 2 B).

$\mathrm{O}$ número médio de capulhos colhidos por planta não foi afetado significativamente pela poda apical,

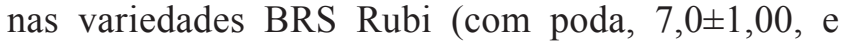
sem poda, 8,3 $\pm 0,33$ ) e BRS 201 (com poda, 4,6 60,3 e sem poda, $5,6 \pm 0,33)$, tendo-se constatado apenas diferenças significativas para o número de capulhos entre as variedades, com maior número encontrado na BRS Rubi $(\mathrm{p}<0,01)$.

As médias das três parcelas do material retirado com a poda apical, nos $528 \mathrm{~m}^{2}$ da área experimental foram: 48,0 $\pm 3,40 \mathrm{~kg}$, para a BRS 201; e $32,1 \pm 4,11 \mathrm{~kg}$, para a BRS Rubi.

A poda I retirou, em média, 10,5 folhas do ponteiro por planta das variedades BRS 201 e BRS Rubi, das quais $49,6 \%$ infestadas pelo pulgão, e 1,7\% pelo ácaro-vermelho (Tabela 2). Nas folhas, haviam 3,3 adultos de mosca-branca (Bemisia tabaci) e 2,8 lagartas do curuquerê (Alabama argillacea e

Tabela 1. Médias \pm erro-padrão da percentagem de folhas infestadas com pulgão e ácaro-vermelho retiradas pela poda apical, em plantas de algodão das variedades de fibra colorida e fibra branca, na safra 2008, em Paudalho, $\mathrm{PE}^{(1)}$.

\begin{tabular}{|c|c|c|c|c|}
\hline \multirow[t]{2}{*}{ Variedade } & \multicolumn{2}{|c|}{ Percentagem de folhas com pulgão } & \multicolumn{2}{|c|}{ Percentagem de folhas com ácaro-vermelho } \\
\hline & Poda I ${ }^{(2)}$ & Poda II & Poda I & Poda II \\
\hline BRS 201 & $44,1 \pm 4,63 \mathrm{a}(26)^{(3)}$ & $56,0 \pm 7,13 \mathrm{a}(28)$ & $1,7 \pm 0,50 \mathrm{~b}(26)$ & $7,5 \pm 2,33 \mathrm{a}(28)$ \\
\hline BRS Rubi & $44,5 \pm 4,66 b(28)$ & $64,7 \pm 4,93 \mathrm{a}(28)$ & $1,5 \pm 0,46 b(28)$ & $9,6 \pm 2,14 \mathrm{a}(28)$ \\
\hline BRS Safira & $49,7 \pm 4,50 \mathrm{~b}(23)$ & $91,8 \pm 2,16 \mathrm{a}(31)$ & $0,9 \pm 0,51 b \quad(23)$ & $15,8 \pm 3,07 \mathrm{a}(31)$ \\
\hline BRS Verde & $54,7 \pm 3,25 b \quad(19)$ & $72,4 \pm 4,55 \mathrm{a}(26)$ & $1,3 \pm 0,61 b(19)$ & $22,0 \pm 3,41 \mathrm{a}(26)$ \\
\hline
\end{tabular}

${ }^{(1)}$ Médias seguidas de letras iguais, entre tratamentos (podas), não diferem pelo teste Tukey, a $5 \%$ de probabilidade. ${ }^{(2)}$ Poda I, $50 \%$ de maçãs maduras; Poda II, primeiros capulhos. ${ }^{(3)}$ Valores entre parênteses correspondem ao número de folhas retiradas pela poda e analisadas. 
Anomis impasta). O material retirado pela poda apical produziu um número similar de botões florais e maçãs menores que $1 \mathrm{~cm}$ entre as variedades. Resultado semelhante foi encontrado quanto à percentagem de botões florais e maçãs removidas atacadas pelo bicudo-do-algodoeiro, Anthonomus grandis (Figura 3 A e B), com 46 e $55 \%$ dos botões retirados com orifícios de oviposição ou alimentação do bicudo, respectivamente.

O número de nós retirados com a poda apical, obtido por diferença com o número encontrado nas plantas sem poda, foi semelhante nas duas localidades para as quatro variedades plantadas na safra 2008, com média de cinco nós no ramo monopodial. Assim, esse valor pode ser usado como referência para a recomendação da poda apical. Esse valor não variou entre épocas de realização da poda, o que indica que a planta não apresentou desenvolvimento significativo do ramo monopodial entre as podas I e II. No entanto, foi observado que, em consequência das melhores condições edafoclimáticas na Zona da Mata (Paudalho), plantas de algodão produziram ramos simpodiais desenvolvidos que também devem ter a parte apical retirada durante a poda.

A produção de botões florais é reduzida com a maturação fisiológica da planta, que direciona a energia disponível para a formação e maturação das maçãs no baixeiro (Wullschleger \& Oosterhuis, 1990; Soares et al., 1999). Este fato, aliado à abscisão natural dessas estruturas, no período compreendido entre a realização das duas podas, resultou em número semelhante de botões retirados entre as duas idades de poda. Os resultados obtidos com as podas, na safra de 2008, permitiram determinar que a poda de 2009 fosse feita quando as plantas apresentassem $50 \%$ de maçãs maduras, para eliminar a mesma quantidade de folhas e botões florais nas variedades testadas.

A remoção de folhas atacadas por pulgão e ácaro-vermelho, bem como adultos da mosca-branca e lagartas do curuquerê, em ambas as safras, mostram que a poda apical elimina importantes pragas. Entretanto, as variedades e as idades fenológicas influenciaram o número de insetos-praga removidos em cada poda (Tabelas 1 e 2).
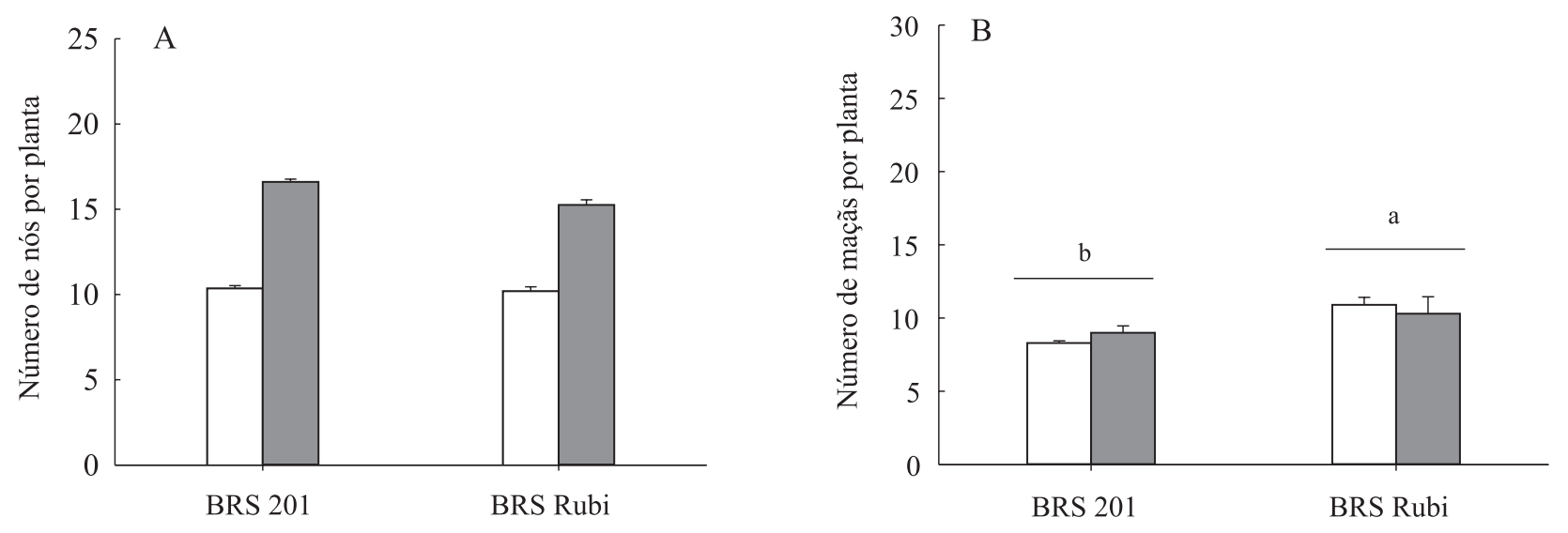

$\square$ Com poda $\square$ Sem poda

Figura 2. Número de nós e de maçãs em plantas de algodão, após a realização ou não da poda apical, na safra 2009, em Surubim, PE. Barras (média \pm erro-padrão) sob letras diferentes, em B, diferem pelo teste de Fisher, a 1\% de probabilidade.

Tabela 2. Médias \pm erro-padrão da percentagem de folhas infestadas e do número de insetos eliminados pela poda apical, em plantas com 50\% das maçãs maduras (Poda I), nas variedades BRS 201 e BRS Rubi, na safra 2009, em Surubim, PE ${ }^{(1)}$.

\begin{tabular}{|c|c|c|c|c|}
\hline \multirow[t]{2}{*}{ Variedade } & \multicolumn{2}{|c|}{ Percentagem de folhas infestadas } & \multicolumn{2}{|c|}{ Número de insetos por folha retirada } \\
\hline & Pulgão & Ácaro-vermelho & Mosca-branca & Curuquerê \\
\hline BRS 201 & $38,6 \pm 4,85 \mathrm{a}(11)^{(2)}$ & $0,2 \pm 0,26 \mathrm{a}(11)$ & $0,3 \pm 0,20 \mathrm{a}$ & $0,6 \pm 0,04 \mathrm{a}$ \\
\hline BRS Rubi & $60,7 \pm 11,00 \mathrm{a}(10)$ & $3,2 \pm 2,92 \mathrm{a}(10)$ & $0,9 \pm 0,28 \mathrm{a}$ & $0,3 \pm 0,11 b$ \\
\hline
\end{tabular}

${ }^{(1)}$ Médias \pm erro-padrão seguidas de letras iguais, nas colunas, entre variedades, não diferem pelo teste t, a $5 \%$ probabilidade. ${ }^{(2)}$ Valores entre parênteses correspondem ao número de folhas retiradas pela poda e analisadas. 

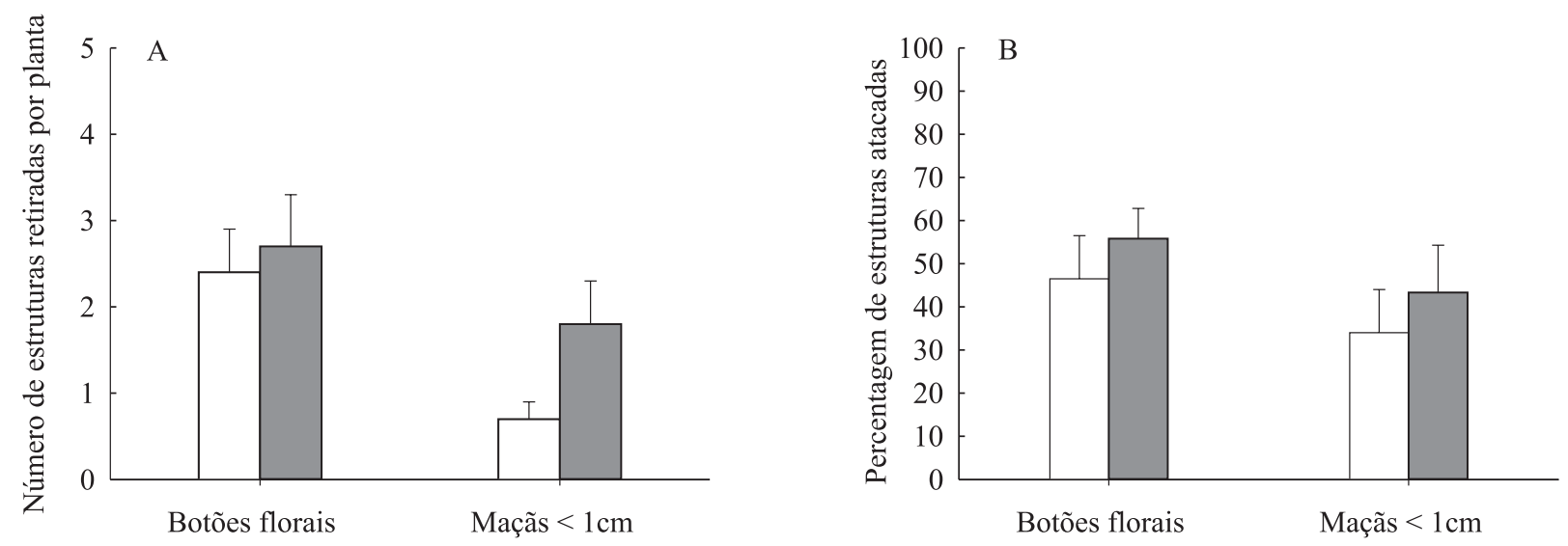

$$
\text { BRS } 201 \quad \square \text { BRS Rubi }
$$

Figura 3. Número de estruturas retiradas por planta, por meio da poda apical (A), e percentagem de estruturas atacadas pelo bicudo (B), na safra 2009, em Surubim, PE. Barras (média \pm erro-padrão) não apresentam diferença significativa pelo teste $\mathrm{t}$, a $5 \%$ probabilidade.

A quantidade de estruturas reprodutivas eliminadas com a poda, na safra 2009, parece estar correlacionada a características intrínsecas das variedades e ao ambiente. Assim, quanto maior o número de estruturas reprodutivas presentes no ápice das plantas, maior a quantidade de estruturas eliminadas atacadas pelo bicudo (Figura 3). As estruturas reprodutivas são atacadas para oviposição, desenvolvimento das larvas e alimentação, e a remoção pela poda apical dos botões florais e das maçãs atacadas tem efeito direto sobre a população do bicudo. Este resultado corrobora Showler $(2004,2005)$, que observaram que uma maior quantidade de estruturas produzidas no ápice da planta pode atrair e aumentar a população de adultos do bicudo.

Para o manejo de pragas, a época mais apropriada para a poda apical é aquela que possibilita a retirada da maior quantidade de estruturas que servem como alimento e abrigo para pragas. No caso de maior incidência de pragas que infestam botões florais, a poda I, realizada com $50 \%$ de maçãs maduras, determinada no estudo realizado na safra de 2008 e aplicada na safra de 2009, pode ser mais eficiente por ser próxima ao pico de produção dessas estruturas que não originarão capulhos. Além disso, a quantidade de folhas recém-desenvolvidas presente nos ponteiros das plantas por ocasião da poda, independentemente da época em que é realizada, pode ter impacto significativo nas populações de insetos-praga. Isto ocorre porque populações de pulgões, ácaros, moscas-brancas e lepidópteros empregam as folhas terminais da planta de algodão como alimento ou como habitat durante parte do seu ciclo de vida (Wilson, 1993; Chu et al., 2001; Fernandes et al., 2001; Santos at al., 2008a).

Como não houve efeito significativo da poda no número de maçãs remanescentes após as podas, conclui-se que as épocas de poda não afetam as estruturas reprodutivas, que já estão presentes na parte intermediária e basal das plantas. A produção de capulhos após a realização das podas foi semelhante, embora tenha variado entre as variedades coloridas (BRS Rubi, BRS Safira e BRS Verde) e a variedade de fibra branca (BRS 201).

A poda apical pode ser considerada semelhante à utilização de dessecantes, em lavouras conduzidas nos moldes da agricultura empresarial. A poda apical de estruturas que não originarão capulhos, portanto, tornase viável como uma prática que visa reduzir a quantidade de substrato para pragas importantes, que utilizam essas partes da planta para alimentação e oviposição.

\section{Conclusões}

1. Nas condições do Semiárido, a época apropriada para a realização da poda apical do algodoeiro ocorre quando as plantas têm $50 \%$ de maçãs maduras.

2. A realização da poda apical não afeta a produção e a qualidade da fibra do algodoeiro, quando realizada 
com $50 \%$ de maçãs maduras ou na abertura do primeiro capulho.

3. A poda apical remove estruturas vegetativas e reprodutivas que contém um significativo número de insetos e ácaros da parte apical do algodoeiro que, dessa forma, são removidos da lavoura.

\section{Agradecimentos}

À Fundação de Amparo à Ciência e Tecnologia do Estado de Pernambuco, pela concessão de bolsa; e à Financiadora de Estudos e Projetos, pelo apoio financeiro; à Rede de Diagnóstico e Ação Multidisciplinar para a Sustentabilidade do Algodão em Pernambuco e ao Banco do Nordeste, pelo apoio ao projeto de algodoeiro colorido no Semiárido.

\section{Referências}

ALMEIDA, R.P. de; SILVA, C.A.D. da; RAMALHO, F. de S. Manejo integrado de pragas do algodoeiro no Brasil. In: BELTRÃO, N.E. de M.; AZEVEDO, D.M.P. de. (Ed.). O agronegócio do algodão no Brasil. 2.ed. rev. amp. Brasília: Embrapa Informação Tecnológica, 2008. p.1035-1098.

ARRUDA, F.P. de; ANDRADE, A.P. de; SILVA, I. de F. da; PEREIRA, I.E.; GUIMARÃES, M.A.M. Emissão/abscisão de estruturas reprodutivas do algodoeiro herbáceo cv. CNPA 7H: efeito do estresse hídrico. Revista Brasileira de Engenharia Agrícola e Ambiental, v.6, p.21-27, 2002.

BEDNARZ, C.W.; ROBERTS, P.M. Spatial yield distribution in cotton following early-season floral bud removal. Crop Science, v.41, p.1800-1808, 2001.

BELTRÃO, N.E. de M.; CARVALHO, L.P. de. Algodão colorido no Brasil, e em particular no Nordeste e no Estado da Paraíba. Campina Grande: Embrapa Algodão, 2004. 17p. (Embrapa Algodão. Documentos, 128).

BELTRÃO, N.E. de M.; SOUZA, J.G. de; AZEVEDO, D.M.P. de; LEÃO A.B.; CARDOSO, G.D. Fitologia do algodoeiro herbáceo: sistemática, organografia e anatomia. In: BELTRÃO, N.E. de M.; AZEVEDO D.M.P. de (Ed.). O agronegócio do algodão no Brasil. 2.ed. rev. amp. Brasília: Embrapa Informação Tecnológica, 2008. p.183-217.

BROWN, R.S.; OOSTERHUIS, D.M.; BOURLAND, F.M.; COKER, D.L. Removal of cotton fruit by chemical and physical means at insecticide termination to improve yields. In: BELTWIDE COTTON CONFERENCE, 2001, Memphis. Proceedings. Memphis: National Cotton Council, 2001. p.544-546.

CARVALHO, L.P. Contribuição do melhoramento ao cultivo do algodão. In: BELTRÃO, N.E. de M.; AZEVEDO, D.M.P. de (Ed.). O agronegócio do algodão no Brasil. 2.ed. rev. amp. Brasília: Embrapa Informação Tecnológica, 2008. p.273-297.
CHU, C.C.; FREEMAN, T.P.; BUCKNER, J.S.; HENNEBERRY, T.J.; NELSON, D.R.; NATWICK, E. Susceptibility of upland cotton cultivars to Bemisia tabaci biotype B (Homoptera: Aleyrodidae) in relation to leaf age and trichome density. Annals of the Entomological Society of America, v.94, p.743-749, 2001.

DEGUINE, J.P.; GOZE, E.; LECLANT, F. The consequences of late outbreaks of the aphid Aphis gossypii in cotton growing in Central Africa: towards a possible method for the prevention of cotton stickiness. International Journal of Pest Management, v.46, p.85-89, 2000.

DENG, S.H.; JIANG, G.Z.; PAN, X.K. Physiological and developmental effects of cotton plants after early squares removing and the mechanism of yield increase and good fiber quality. Acta Agronomica Sinica, v.17, p.401- 408, 1991.

FERNANDES, A.M.V.; FARIAS, A.M.I.; SOARES, M.M.M.; VASCONCELOS, S.D. Desenvolvimento do pulgão Aphis gossypii Glover (Hemiptera: Aphididae) em três cultivares de algodão herbáceo Gossypium hirsutum L. r. latifolium Hutch. Neotropical Entomology, v.30, p.467-470, 2001.

GALLO, D.; NAKANO, O.; SILVEIRA NETO, S.; CARVALHO, R.P.L.; BATISTA, G.C. de; BERTI FILHO, E.; PARRA, J.R.; ZUCCHI, R.A.; ALVES, S.B.; VENDRAMIM, J.D.; MARCHINI, L.C.; LOPES, J.R.S.; OMOTO, C. Entomologia agrícola. Piracicaba: Fealq, 2002.920p.

KIM, M.J.; OOSTERHUIS, D.M. Effect of upper-canopy square removal before and after $\mathrm{NAWF}=5$ plus 350 heat units on carbon partitioning from upper-canopy leaves to bolls lower in the canopy. In: COTTON RESEARCH MEETING AND SUMMARIES OF RESEARCH IN PROGRESS, 1998, Fayetteville. Proceedings. Fayetteville: University of Arkansas, 1998. p.174-176. (Special report, 188).

NEVES, R.C.S.; TORRES, J.B.; VIVAN, L.M. Reproduction and dispersal of wing-clipped predatory stinkbugs, Podisus nigrispinus in cotton fields. BioControl, v.54, p.9-17, 2009.

OBASI, M.O.; MSAAKPA, T.S. Influence of topping, side branch pruning and hill spacing on growth and development of cotton (Gossypium barbadense L.) in the southern Guinea savanna location of Nigeria. Journal of Agriculture and Rural Development in the Tropics and Subtropics, v.106, p.155-165, 2005.

RAMALHO, F.S. Cotton pest-management. Part 4. A Brazilian perspective. Annual Review of Entomology, v.39, p.563-578, 1994.

RAMALHO, F.S.; MEDEIROS, R.S.; LEMOS, W.P.; DIAS, J.M.; ZANUNCIO, J.C. Evaluation of Catolaccus grandis (Burks) (Hymenoptera: Pteromalidae) as a biological control agent against cotton boll weevil. Journal of Applied Entomology, v.124, p.359-364. 2000.

SANTOS, R.F. dos; KOURI, J.R.M.; SANTOS, J.W. O agronegócio do algodão: crise e recuperação no mercado brasileiro da matéria-prima agrícola. In: BELTRÃO, N.E. de M; AZEVEDO, D.M.P. de (Ed.). O agronegócio do algodão no Brasil. 2.ed. rev. amp. Brasília: Embrapa Informação Tecnológica, 2008a. p.33-60.

SANTOS,R.L.dos;TORRES,J.B.;BASTOS,C.S.Desenvolvimento e crescimento populacional de Alabama argillacea em algodão de fibra branca e colorida. Pesquisa Agropecuária Brasileira, v.43, p.457-463, 2008b. 
SAS INSTITUTE. SAS/STAT user's guide. Version 8.02. Cary: SAS Institute, 2001.

SHOWLER, A.T. Influence of cotton fruit stages as food sources on boll weevil (Coleoptera: Curculionidae) fecundity and oviposition. Journal of Economic Entomology, v.97, p.1330-1334, 2004.

SHOWLER, A.T. Relationships of different cotton square sizes to boll weevil (Coleoptera: Curculionidae) feeding and oviposition in field conditions. Journal of Economic Entomology, v.98, p.1572 -1579, 2005.

SILVIE, P.J.; RENOU, A.; BADJI, C.A. Controle das pragas do algodão por práticas culturais e manipulação do habitat. Revista Brasileira de Oleaginosas e Fibrosas, v.10, p.1183-1196, 2006.

SOARES, J.J.; LARA, F.M.; SILVA, C.A.D. da; ALMEIDA, R.P. de; WANDERLEY, D.S. Influência da posição do fruto na planta sobre a produção do algodoeiro. Pesquisa Agropecuária Brasileira, v.34, p.755-759, 1999.
SUNDARAMURTHY, V.T. The integrated insect management system and its effects on environment and productivity of cotton. Outlook on Agriculture, v.31, p.95-105, 2002.

TORRES, J.B.; RUBERSON, J.R. Toxicity of thiamethoxam and imidacloprid to Podisus nigrispinus (Dallas) (Heteroptera: Pentatomidae) nymphs associated to aphid and whitefly control in cotton. Neotropical Entomology, v.33, p.99-106, 2004.

WANDERLEY, P.A.; RAMALHO, F.S.; ZANUNCIO, J.C. Thermal requirements and development of Bracon vulgaris, a parasitoid of the cotton boll weevil. Phytoparasitica, v.35, p.336-345, 2007.

WILSON, L.J. Spider mites (Acari: Tetranychidae) affect yield and fiber quality of cotton. Journal of Economic Entomology, v.86, p.566-585, 1993.

WULLSCHLEGER, S.D.; OOSTERHUIS, D.M. Photosynthetic carbon production and use by developing cotton leaves and boll. Crop Science, v.30, p.1259-1264, 1990.

$\overline{\text { Recebido em } 5 \text { de abril de } 2010 \text { e aprovado em } 22 \text { de novembro de } 2010}$ 